\title{
Global epidemiology of invasive meningococcal disease
}

\author{
Rabab Z Jafri ${ }^{1}$, Asad Ali ${ }^{1 *}$, Nancy E Messonnier ${ }^{2}$, Carol Tevi-Benissan ${ }^{3}$, David Durrheim ${ }^{4,5}$, Juhani Eskola ${ }^{6}$, \\ Florence Fermon ${ }^{7}$, Keith P Klugman ${ }^{8,9}$, Mary Ramsay ${ }^{10}$, Samba Sow ${ }^{11,12}$, Shao Zhujun ${ }^{13}$, Zulfiqar A Bhutta \\ and Jon Abramson ${ }^{14}$
}

\begin{abstract}
Neisseria meningitidis is one of the leading causes of bacterial meningitis globally and can also cause sepsis, pneumonia, and other manifestations. In countries with high endemic rates, the disease burden places an immense strain on the public health system. The worldwide epidemiology of invasive meningococcal disease (IMD) varies markedly by region and over time. This review summarizes the burden of IMD in different countries and identifies the highest-incidence countries where routine preventive programs against Neisseria meningitidis would be most beneficial in providing protection. Available epidemiological data from the past 20 years in World Health Organization and European Centre for Disease Prevention and Control collections and published articles are included in this review, as well as direct communications with leading experts in the field. Countries were grouped into high-, moderate-, and low-incidence countries. The majority of countries in the high-incidence group are found in the African meningitis belt; many moderate-incidence countries are found in the European and African regions, and Australia, while low-incidence countries include many from Europe and the Americas. Priority countries for vaccine intervention are high- and moderate-incidence countries where vaccine-preventable serogroups predominate. Epidemiological data on burden of IMD are needed in countries where this is not known, particularly in South- East Asia and Eastern Mediterranean regions, so evidence-based decisions about the use of meningococcal vaccines can be made.
\end{abstract}

Keywords: Meningococcus, Neisseria meningitidis, Invasive meningococcal disease, Meningitis, Epidemiology, Meningitis belt

\section{Introduction}

Neisseria meningitidis is one of the leading causes of bacterial meningitis globally and can also cause sepsis, pneumonia, and other localized infections. There are 12 serogroups, but the majority of invasive meningococcal infections are caused by organisms from the A, B, C, X, Y, or W-135 serogroups. The annual number of invasive disease cases worldwide is estimated to be at least 1.2 million, with 135,000 deaths related to invasive meningococcal disease (IMD) [1,2]. In countries with high endemicity, the disease burden places an immense strain on the public health system. The risk of long-term disabling sequelae, including cognitive deficit, bilateral hearing loss, motor deficit, seizures, visual impairment, hydrocephalus, and

\footnotetext{
* Correspondence: asad.ali@aku.edu

'Department of Pediatrics and Child Health, Division of Women and Child Health, Aga Khan University, Stadium Road, Karachi, Pakistan

Full list of author information is available at the end of the article
}

loss of limbs due to tissue necrosis, are highest in lowincome countries, where the burden of bacterial meningitis is greatest [3].

To combat IMD, many industrialized countries have included different formulations of meningococcal vaccine in their routine immunization programs. A vaccine against serogroup A has recently been introduced in the African meningitis belt, an area extending from Senegal in the west to Ethiopia in the east $[4,5]$. However, meningococcal vaccines remain underutilized globally, particularly in resource-limited countries outside the African meningitis belt. To provide cost effective recommendations about the use of meningococcal vaccines, the country-specific burden of IMD must be established [6]. A comprehensive review of IMD incidence, including all countries with at least a basic surveillance infrastructure reporting IMD cases, was conducted. The review provides the most recently published attack rates, predominant serogroups, and

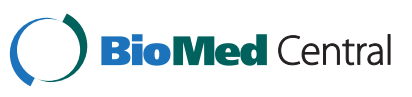

(c) 2013 Jafri et al.; licensee BioMed Central Ltd. This is an Open Access article distributed under the terms of the Creative Commons Attribution License (http://creativecommons.org/licenses/by/2.0), which permits unrestricted use, distribution, and reproduction in any medium, provided the original work is properly cited. 
at-risk groups from over 80 countries and organizes the data according to priority groups for vaccine intervention.

\section{Methods}

\section{Search strategy and selection criteria}

Our sources for the epidemiological data included the National Library of Medicine (PubMed), the World Health Organization (WHO) website of the Weekly Epidemiological Record, and the European Centre for Disease Prevention and Control. We searched PubMed with the following key terms: ("Neisseria meningitidis") OR ("meningococcal") OR ("meningococcemia") OR ("meningococcus"). The search was limited to studies of humans, studies published in English, and dates of publication from January 1, 1990, to December 31, 2010. The initial search yielded 5,336 results from which studies were excluded based on exclusion criteria below. In addition, data were obtained and included from WHO publications in the Weekly Epidemiological Record (WER) for the latest figures from 14 African meningitis belt countries. The European Union Invasive Bacterial Infections Surveillance Network (EU-IBIS), which is maintained by the European Centre for Disease Prevention and Control, was accessed for updated figures for European countries and these data were also included. We searched reference lists in all identified articles for additional articles, and reviewed abstracts and titles and selected studies if it seemed they included aspects of meningococcal epidemiology. From the above literature search we excluded generic worldwide estimates (except to identify original data references), or studies that were limited to immunology, drug resistance, or other non-epidemiological factors.

\section{Organization of data}

The WHO definition of a meningococcal disease epidemic (>100 cases/100,000 population/year) applies specifically to the meningitis belt. Other countries rarely experience epidemics with these high attack rates. We classified countries according to the level of endemic meningococcal disease as "high," "moderate," and "low" endemicity (Figure 1). This classification is based on country-specific epidemiological data with pre-defined cutoffs of high, moderate, and low endemicity categories and was used by the WHO's Strategic Advisory Group of Experts on Immunizations (SAGE) in its recently updated recommendations on the use of meningococcal vaccines [7].

\section{Results}

Epidemiology of meningococcal disease at country level

Data on incidence of meningococcal disease are presented below in Tables 1, 2 and 3. Countries are grouped into priority regions according to the definitions above, using national and published data from the last 20 years. Countries not listed in the table have insufficient available IMD epidemiological data to permit accurate classification.

Significant gaps in data limit description of IMD epidemiology in some parts of the world. In many countries with IMD surveillance, extensive targeted vaccine development and increasing coverage has decreased the burden of disease. In some endemic countries without vaccination, high IMD attack rates continue. The specific regional epidemiology is summarized in Figure 2 and described in terms of WHO regions below.

\section{African region}

The African Meningitis Belt, originally characterized by Lapeysonnie in 1963 [5] and modified in 1987, has the highest annual incidence of meningococcal disease in the world with superimposed frequent epidemics that constitute a major public health burden. Outbreaks in the subSaharan region coincide with the dry season, which has led to a hypothesis for the potential role of low humidity and seasonal dust-wind blowing from the Sahara (the Harmattan) in damaging the mucosa and producing irritant coughing that aids transmission $[34,43]$.

Twenty-five countries in the African region with an extremely high incidence of meningococcal disease constitute the meningitis belt. To rapidly detect the frequent epidemics, a strong surveillance system exists that monitors the number of cases on an ongoing basis for rapid response. This region has recently benefitted from a major alliance of international health bodies that have developed and are deploying an affordable and effective vaccine against serogroup A meningococcus, which causes the majority of disease in this area, at population level [44].

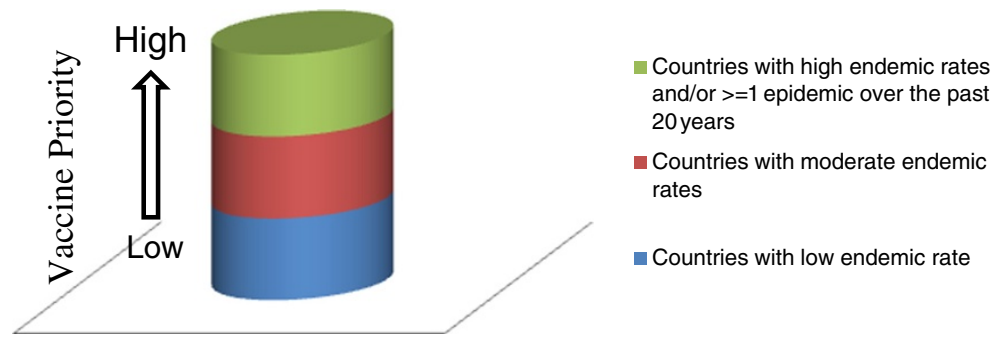

Figure 1 A categorization of countries according to IMD attack rates. 
Table 1 Countries with high endemic rates ( $>10$ cases/100,000 population) and/or $>=1$ epidemic over the last 20 years

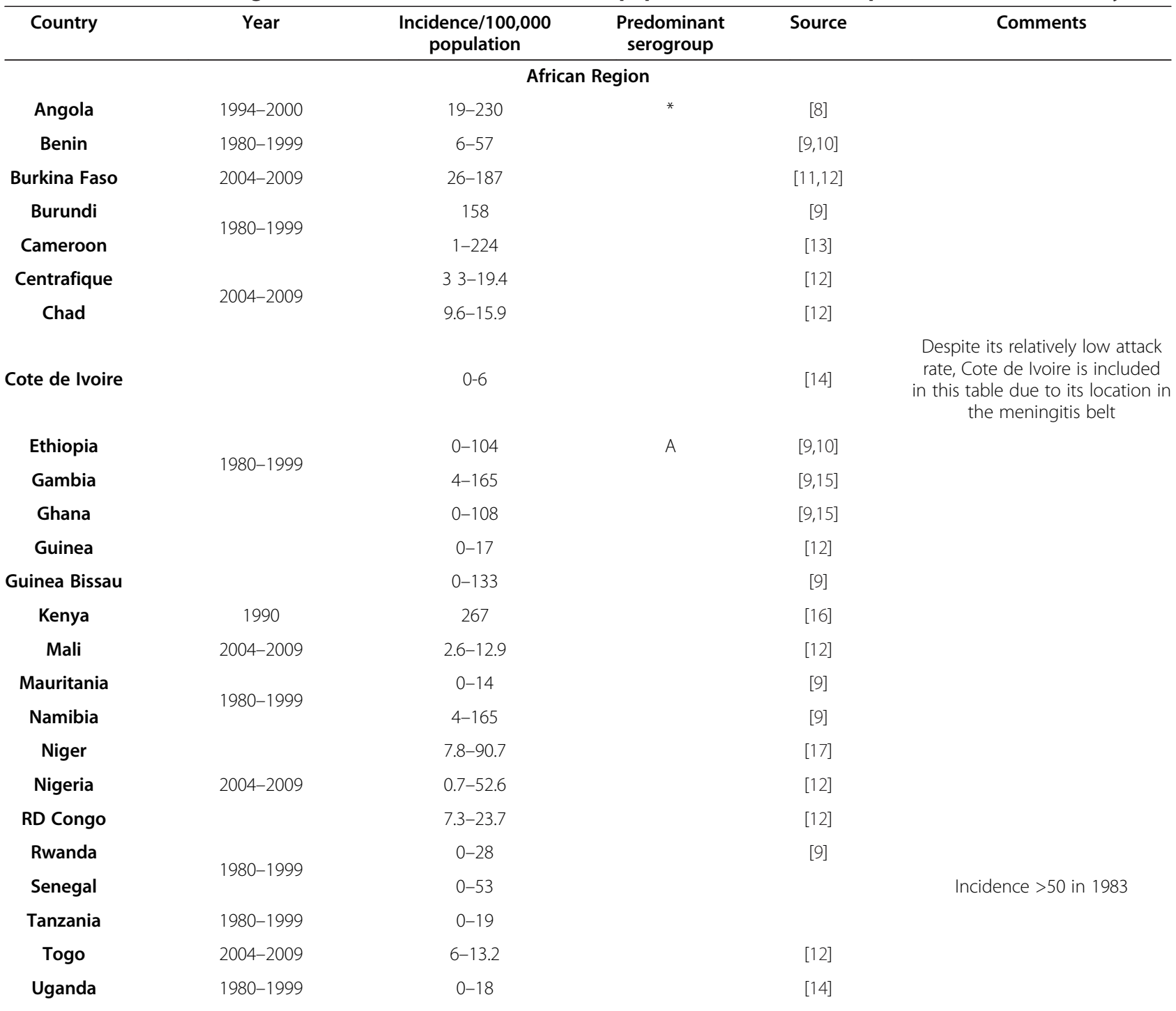

Eastern Mediterranean Region

Despite lack of data Sudan is included in this table due to its location in the meningitis belt

225 cases in month after 2000 Hajj season. Data from Saudi Arabia mostly includes cases from the Hajj season.

\section{European Region}

No country in this region is in the high rate category

Region of the Americas

30 (pre-vaccine)

Uruguay
2001

1.6 (post-vaccine)
Vaccine comprising serogroup C capsular polysaccharide and the outer membrane vesicles of serogroup B meningococcus was used 
Table 1 Countries with high endemic rates ( $>10$ cases/100,000 population) and/or $>=1$ epidemic over the last 20 years (Continued)

\begin{tabular}{|c|c|c|c|c|c|}
\hline \multicolumn{6}{|c|}{ South-East Asia Region } \\
\hline \multicolumn{6}{|c|}{ No country in this region is in the high rate category } \\
\hline \multicolumn{6}{|c|}{ Western Pacific Region } \\
\hline \multirow{2}{*}{ New Zealand } & \multirow{2}{*}{$1991-2000$} & 17.4 (pre-vaccine) & $\mathrm{B}$ & [201 & \multirow{2}{*}{$\begin{array}{c}\text { An OMV vaccine for Serogroup } \\
\text { B was introduced in } 2004\end{array}$} \\
\hline & & 2.6 (post-vaccine) & B & {$[20]$} & \\
\hline Mongolia & 1994-1995 & $80-90$ & A & {$[21]$} & \\
\hline
\end{tabular}

* Data not available.

Serogroup X, previously a rare cause of sporadic meningitis, has been responsible for outbreaks between 2006 and 2010 in Kenya, Niger, Togo, Uganda, and Burkina Faso, the latter with at least 1,300 cases of serogroup $\mathrm{X}$ meningitis among the 6,732 reported annual cases [45].

South Africa is included in the moderate-endemicity group, while other countries in this region do not have adequate data to enable derivation of a population-based estimate of their true incidence rates.

\section{Eastern Mediterranean region}

Sudan and Saudi Arabia have high endemic rates of serogroup A disease, and have also experienced outbreaks in recent years during the hajj season with serogroup W-135. Other countries in this region do not have adequate data to permit a population-based estimate of true incidence, although outbreaks have been reported among returning travelers from Hajj.

\section{European region}

With the exception of a few countries in the eastern part of the European Region, good surveillance data are available from most European countries. Serogroup B and C are responsible for the majority of disease, and implementation of a meningococcal immunization program with adequate vaccine coverage has contributed to decreasing endemic rates so that no country now falls in the high-endemicity group. Fifteen countries from this region are classified as moderate endemicity and 18 as low. Recent epidemiological surveillance indicates an increase of serogroup Y IMD in some parts of Europe, which is now the third most common serogroup after B and C [23].

\section{Region of the Americas}

Uruguay remains the only country from this region to have experienced high rates of IMD within the past 20 years. In 2001, it suffered a peak incidence rate of meningococcal disease due to serogroup $B$ and this prompted the introduction of the Cuban outer membrane vesicle (OMV) B vaccine with good coverage and a sharp decline in incidence in subsequent years. Brazil and Cuba have experienced moderate incidence rates, but have also seen significant benefit from the introduction of meningococcal vaccines in their populations
[29]. Argentina, Canada, Chile, Columbia, Mexico, the United States, and Venezuela have experienced low levels of IMD in the timeframe defined by this review. Serogroup Y emerged in Colombia and Venezuala, where it became the common disease-causing serogroup in 2006 [19]. The US has a universal meningococcal vaccine (conjugated quadrivalent vaccine given to adolescents) and Canada also recommends a booster dose in this age group following primary immunization at 12 months of age. Other countries in this region do not have adequate data to allow population-based estimates of their true incidence.

\section{South-East Asia Region}

Korea and Thailand are the only countries from this region with published population-based estimates, which demonstrate low endemic rates. India has experienced repeated serogroup A epidemics, the most recent in 2005, but data are mostly available only from large city centers [46]. Sporadic and incomplete data from India, Bangladesh, Indonesia, Nepal, and Pakistan preclude their classification, and no data are available from Sri Lanka [36].

\section{Western Pacific}

New Zealand and Mongolia have recorded high IMD endemicity. New Zealand experienced an outbreak of serogroup B disease until an aggressive campaign with the OMV vaccine was initiated in 2004 that has contributed in part to lowering the incidence. Mongolia experienced serogroup A epidemics in the early 1990s. Australia currently experiences predominantly serogroup $\mathrm{B}$ disease with moderate attack rates after the introduction of a serogroup $C$ vaccine saw a marked decline in rates of disease due to the $\mathrm{C}$ serogroup. China, Japan, Korea, Philippines, Singapore, Taiwan, and Thailand all experience low levels of IMD. Other countries in this region do not have adequate population-based data to allow estimation of their true incidence rates.

\section{Age-specific attack rates}

In many countries with epidemiological data, particularly in Europe and North America, the age distribution of meningococcal disease demonstrates two peaks [6,47-49]. The highest incidence is in infants less than one year of 
Table 2 Countries with moderate endemic rates (2-10 cases/100,000 population per year)

\begin{tabular}{|c|c|c|c|c|c|}
\hline Country & Year & $\begin{array}{c}\text { Incidence/ } \\
100,000 \text { population }\end{array}$ & $\begin{array}{l}\text { Predominant } \\
\text { serogroup }\end{array}$ & Source & Comments \\
\hline \multicolumn{6}{|l|}{ African Region } \\
\hline South Africa & $2000-2005$ & $0.8-4$ & B in Western Cape & [22] & \\
\hline \multicolumn{6}{|c|}{ Eastern Mediterranean Region } \\
\hline \multicolumn{6}{|c|}{ No country in this region is in the moderate rate category } \\
\hline \multicolumn{6}{|c|}{ European Region } \\
\hline Belgium & 1999-2010 & $\begin{array}{c}2.9 \text { (pre-vaccine) } \\
0.89 \text { (post-vaccine) }\end{array}$ & $\mathrm{B}, \mathrm{C}$ & {$[23,24]$} & $\begin{array}{l}\text { A conjugate vaccine for group } \\
\text { C was introduced in } 2002\end{array}$ \\
\hline Denmark & 1999-2010 & $1.19-3.5$ & B & {$[23,24]$} & \\
\hline Greece & & $0.49-2.0$ & $\mathrm{C}$ & {$[23,24]$} & $\begin{array}{c}\text { A conjugate vaccine for group } \\
C \text { introduced in } 2001 \text { in pediatric } \\
\text { population[25] }\end{array}$ \\
\hline \multirow[t]{2}{*}{ Ireland } & & 14.3 (pre-vaccine) & $B, C$ & {$[23,24]$} & $\begin{array}{c}\text { A conjugate vaccine for group } \\
\text { C was }\end{array}$ \\
\hline & & 2.19 (post-vaccine) & & & introduced in 2001 \\
\hline \multirow[t]{2}{*}{ Iceland } & & 7.6 (pre-vaccine) & $B, C$ & {$[23,24]$} & $\begin{array}{c}\text { A conjugate vaccine for group } \\
\text { C was }\end{array}$ \\
\hline & & 0.6 (post-vaccine) & & & introduced in 2002 \\
\hline Lithuania & 2004-2010 & $1.4-2.6$ & * & {$[23,24]$} & \\
\hline Luxemburg & 1999-2010 & $0.2-5.68$ & * & {$[23,24]$} & \\
\hline Malta & 1994-2007 & $0.8-8.9$ & $B, C$ & {$[26]$} & 2 peaks in 2000 and 2006 \\
\hline Netherland & 1999-2010 & $\begin{array}{c}3.6 \text { (pre-vaccine) } \\
0.86 \text { (post-vaccine) }\end{array}$ & $B, C$ & {$[23,24]$} & $\begin{array}{l}\text { A conjugate vaccine for group } \\
\text { C was introduced in } 2002\end{array}$ \\
\hline Norway & 1992-2010 & $0.8-4.6$ & B & {$[23,27]$} & \\
\hline Portugal & $2000-2010$ & $0.74-3.0$ & $B, C$ & {$[23,28]$} & \\
\hline Spain & 1999-2010 & $\begin{array}{l}3.52 \text { (pre-vaccine) } \\
0.88 \text { (post vaccine) }\end{array}$ & $\mathrm{B}, \mathrm{C}$ & {$[23,24]$} & $\begin{array}{l}\text { A conjugate vaccine for group } \\
\text { C introduced in } 2001\end{array}$ \\
\hline Switzerland & 1999-2004 & $1.16-2.36$ & C & [24] & $\begin{array}{l}\text { A conjugate vaccine for group } \\
\text { C introduced in } 2005\end{array}$ \\
\hline Turkey & 1997-2005 & $0.3-2.2$ & * & {$[28]$} & \\
\hline United Kingdom & 1999-2010 & $\begin{array}{l}5.4 \text { (pre-vaccine) } \\
1.63 \text { (post vaccine) }\end{array}$ & $B, C$ & {$[23,24]$} & $\begin{array}{l}\text { A conjugate vaccine for group } \\
\text { C introduced in } 1999\end{array}$ \\
\hline \multicolumn{6}{|c|}{ Region of the Americas } \\
\hline Brazil & 1998-2006 & $1-4.5$ & B, now $C$ & [19] & $\begin{array}{c}\text { A combined vaccine against } \\
\text { serogroup B (OMV) and } \\
\text { C (polysaccharide) was introduced } \\
\text { in } 1990\end{array}$ \\
\hline Cuba & 1998-2003 & 3.4-8.5 (pre-vaccine) & B & [29] & $\begin{array}{c}\text { A combined vaccine against } \\
\text { serogroup B (OMV) and C } \\
\text { (polysaccharide) was introduced } \\
\text { in } 1987\end{array}$ \\
\hline
\end{tabular}

South-East Asia Region

No country in this region is in the moderate rate category

Western Pacific Region

$\begin{array}{lllll}\text { Australia } & \text { 1995-2006 } & 3.5-7.9 \text { (pre-vaccine) } & \text { B } & \text { [30] }\end{array} \quad \begin{gathered}\text { A conjugate vaccine for Serogroup } \\ \text { C was introduced in 2003 }\end{gathered}$

\footnotetext{
* Data not available.
} 
Table 3 Countries with low endemic rates ( $<2$ case/100,000 population per year)

\begin{tabular}{|c|c|c|c|c|}
\hline Country & Year & $\begin{array}{c}\text { Incidence/ } \\
100,000 \text { population }\end{array}$ & Predominant serogroup & Source \\
\hline \multicolumn{5}{|c|}{ African Region } \\
\hline \multicolumn{5}{|c|}{ No country in this region is in the low rate category } \\
\hline \multicolumn{5}{|c|}{ European Region } \\
\hline Austria & 1999-2010 & $1.02-1.2$ & $B, C$ & {$[23,24]$} \\
\hline Bulgaria & $2000-2010$ & $0.11-1.1$ & * & {$[23,28]$} \\
\hline Croatia & $1997-2005$ & $0.7-1.3$ & * & [28] \\
\hline Cyprus & $1997-2010$ & $0.13-1.7$ & * & {$[23,28]$} \\
\hline Czech Republic & 1999-2010 & $0.57-1.0$ & $B, C$ & {$[23,24]$} \\
\hline Estonia & $2001-2010$ & $0.15-1.6$ & * & {$[23,28]$} \\
\hline Finland & & $0.64-1.1$ & B & \\
\hline France & 1999-2010 & $0.7-1.13$ & $B, C$ & \\
\hline Germany & & $0.47-0.73$ & $B, C$ & \\
\hline Hungary & 2004-2010 & $0.3-0.4$ & * & {$[23,24]$} \\
\hline Italy & 1999-2010 & $0.25-0.55$ & $B, C$ & \\
\hline Latvia & 2004-2008 & $0.25-1.03$ & * & \\
\hline Poland & 1999-2010 & $0.17-0.84$ & B & \\
\hline Serbia & 2000 & 0.9 & * & [28] \\
\hline Slovakia & 2004-2010 & $0.59-0.9$ & * & \\
\hline Slovenia & 1999-2010 & $0.3-1.2$ & * & {$[23,24][23,24]$} \\
\hline \multirow[t]{2}{*}{ Sweden } & 2004-2010 & $0.5-0.7$ & $B, C$ & \\
\hline & \multicolumn{4}{|c|}{ Eastern Mediterranean Region } \\
\hline
\end{tabular}

No country in this region is in the low rate category

Region of the Americas

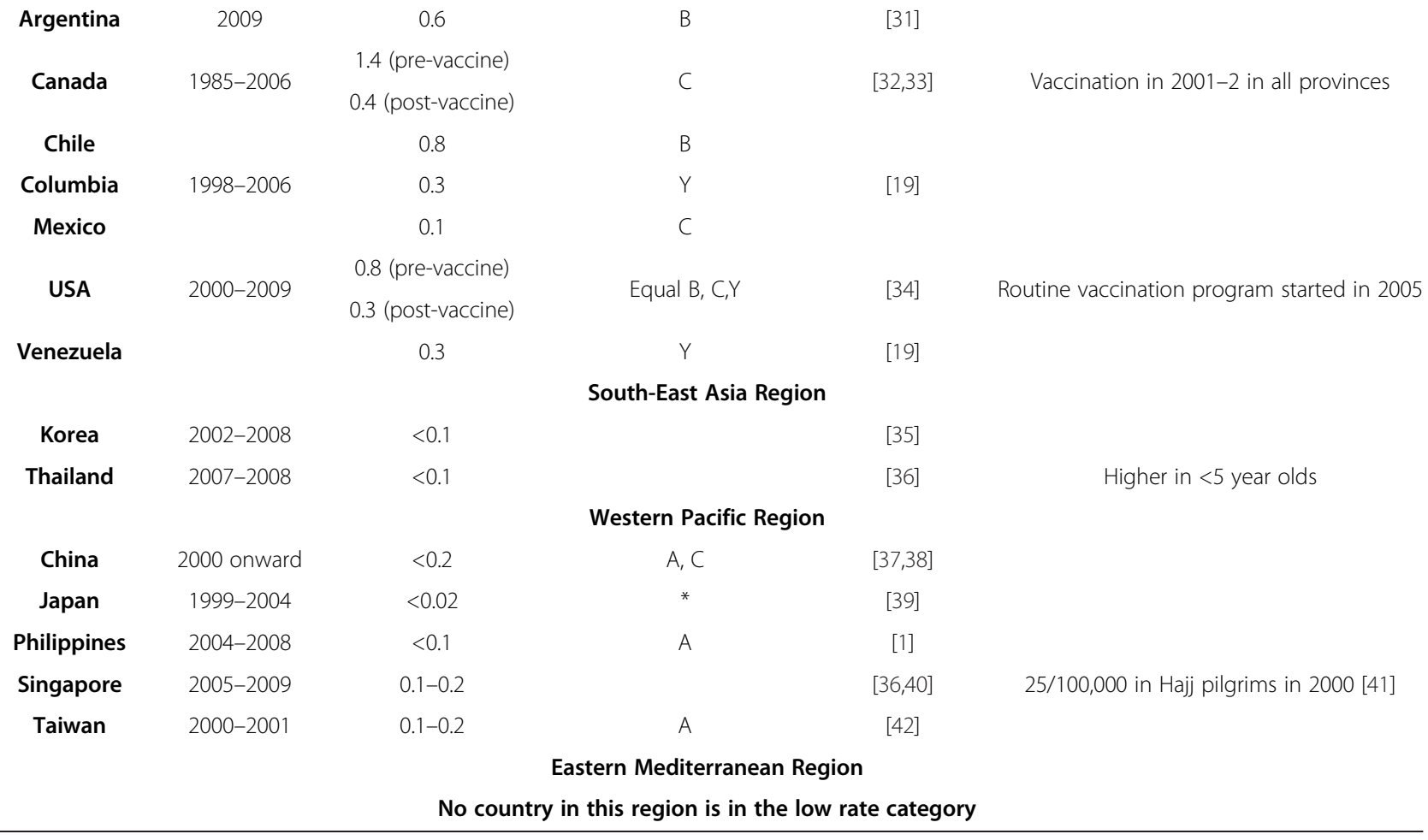




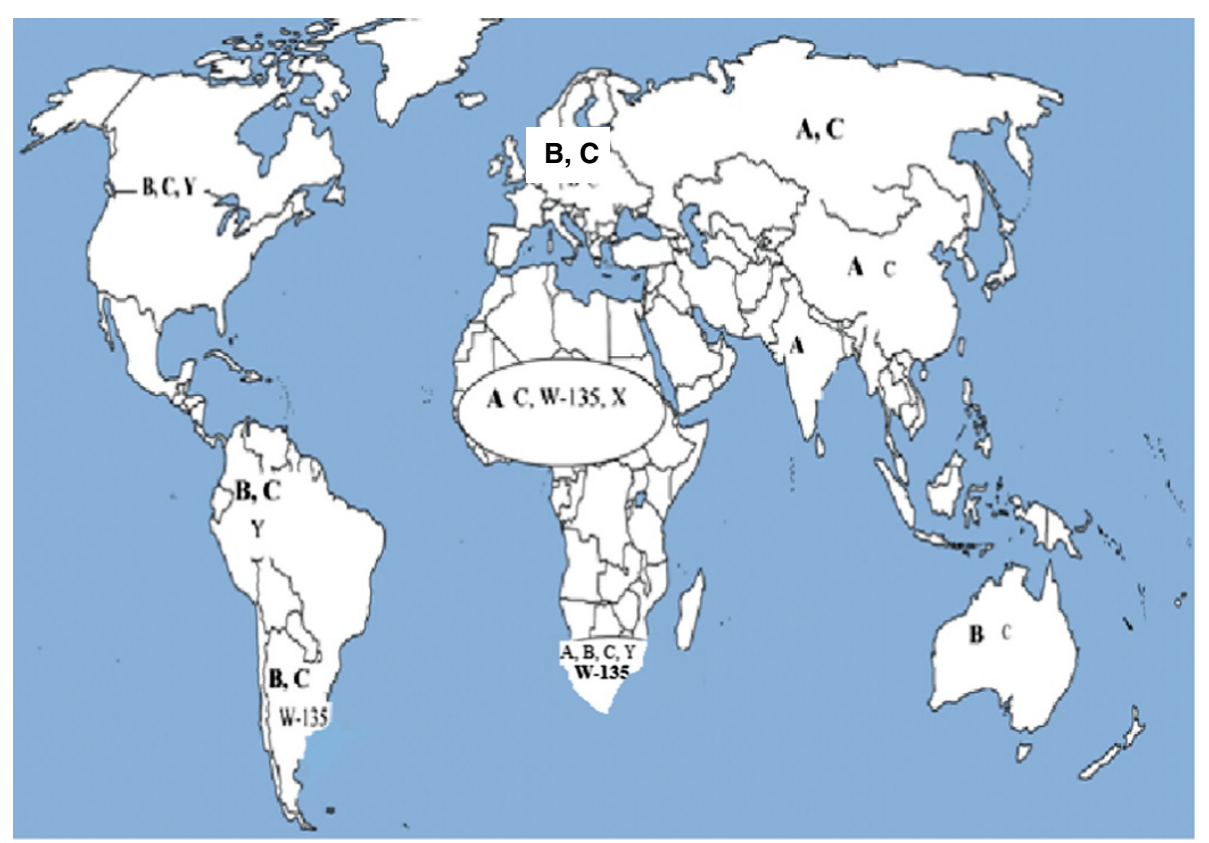

Figure 2 Distribution of common and predominant meningococcal serogroups by region. Predominant strains are highlighted in bold text.

age, and a secondary rise in incidence occurs in adolescents and young adults. In one study in the meningitis belt, the age-incidence did not plateau until the late 20 s. Fifteen years of data from Niger show that children under the age of five were more affected during epidemics when compared to non-epidemic years [50]. However, some studies have suggested a shift toward older age groups during epidemics [51].

The widespread and rapid use of effective antibiotics has contributed to bringing down the case fatality rate of IMD to between 10 and 20 percent, but it is generally higher in developing countries where access to higher levels of care may be delayed [52]. Despite advances in resuscitative techniques, surgical intervention, and critical care, there is a persistent mortality in the early hours of septicemia due to the rapid progression of disease.

\section{Conclusion}

IMD is a serious illness that can be rapidly progressive with resulting significant morbidity and mortality, even with treatment. Vaccines are available for the majority of serogroups that cause disease and have proven effective in reducing the disease incidence in countries that have applied them at the population level. Maximizing the global impact of these vaccines requires having them made available in regions that have the highest disease incidence.

This review used available data to define the burden of meningococcal disease in different countries. Countries were classified based on the disease endemicity, and available data on the most prevalent serogroups were reviewed to permit evidence-based decisions on meningococcal vaccine use. These data helped inform SAGE's new recommendations on the use of meningococcal vaccines. Limitations of the review include exclusion of studies that were not published in English and the absence of an indicator of the quality of surveillance used to derive incidence rates. It is crucial that timely surveillance utilizing new molecular epidemiology tools is implemented to obtain epidemiological data on burden of meningococcal disease in countries where these are not known. With the licensing of a new affordable conjugated vaccine against serogroup A (licensed in Africa) and, more recently, a multicomponent serogroup B vaccine in Europe (January 2013), functioning surveillance will be necessary to monitor the impact of these vaccines through direct immunity and herd protection and allow for optimization of vaccination schedules.

\section{Competing interests}

The authors declare that they have no significant competing interests.

\section{Authors' contributions}

All authors have made active contributions in conceptualizing, drafting, and editing this manuscript. All authors read and approved the final manuscript.

\section{Authors' information}

This manuscript describes the major findings of the meningococcal vaccine working group commissioned by the Strategic Advisory Group of Experts (SAGE) of the WHO.

\section{Author details}

${ }^{1}$ Department of Pediatrics and Child Health, Division of Women and Child Health, Aga Khan University, Stadium Road, Karachi, Pakistan. ${ }^{2}$ Centers for 
Disease Control and Prevention, Atlanta, GA, USA. ${ }^{3}$ Immunisation, Vaccines and Biologicals, World Health Organisation, Geneva, Switzerland. ${ }^{4}$ School of Medicine and Public Health, University of Newcastle, Callaghan, Australia. ${ }^{5}$ Health Protection, Hunter New England Area, Wallsend, Australia. ${ }^{6}$ Finnish National Institute for Health and Welfare (THL), Helsinki, Finland. ${ }^{7}$ International vaccination working group, Médécins Sans Frontières, Paris, France. ${ }^{8}$ Global Health, Rollins School of Public Health, Emory University, Atlanta, GA, USA. ${ }^{9}$ Respiratory and Meningeal Pathogens Research Unit, University of Witwatersrand and Medical Research Council, Johannesburg, South Africa. ${ }^{10}$ Immunisation Department at the Health Protection Agency, Centre for Infections in Colindale, London, UK. ${ }^{11}$ Center for Vaccine Development, Ministry of Health, Bamako, Mali. ${ }^{12}$ School of Medicine, University of Maryland, Baltimore, MD, USA. ${ }^{13}$ Institute for Communicable Disease Control and Prevention, Beijing, People's Republic of China. ${ }^{14}$ Wake Forest School of Medicine, Winston-Salem, NC, USA.

Received: 27 September 2012 Accepted: 6 September 2013 Published: 10 September 2013

\section{References}

1. Rouphael NG, Stephens DS: Neisseria meningitidis: biology, microbiology, and epidemiology. Methods Mol Biol 2012, 799:1-20.

2. Epidemics of meningococcal disease. African meningitis belt, 2001. Wkly Epidemiol Rec 2001, 76:282-288.

3. Edmond K, Clark A, Korczak VS, Sanderson C, Griffiths UK, Rudan I: Global and regional risk of disabling sequelae from bacterial meningitis: a systematic review and meta-analysis. Lancet Infect Dis 2010, 10:317-328.

4. Greenwood BM: The epidemiology of acute bacterial meningitis in tropical Africa. In: Williams JD, Burnie J, editors. Bacterial meningitis. London: Academic Press; 1987. p. 61-91

5. Lapeyssonnie L: [Cerebrospinal Meningitis in Africa]. Bull World Health Organ 1963, 28 Suppl:1-114

6. Harrison LH, Pelton SI, Wilder-Smith A, Holst J, Safadi MA, Vazquez JA, Taha MK LaForce FM, von Gottberg A, Borrow R, Plotkin SA: The Global Meningococcal Initiative: recommendations for reducing the global burden of meningococcal disease. Vaccine 2011, 29:3363-3371.

7. Meningococcal Vaccines: WHO position paper, November 2011. Weekly Epidemiological Record 2011:521-540.

8. Gaspar M, Leite F, Brumana L, Felix B, Stella AA: Epidemiology of meningococcal meningitis in Angola, 1994-2000. Epidemiol Infect 2001, 127:421-424.

9. Molesworth AM, Thomson MC, Connor SJ, Cresswell MP, Morse AP, Shears P, Hart CA, Cuevas LE: Where is the meningitis belt? Defining an area at risk of epidemic meningitis in Africa. Trans R Soc Trop Med Hyg 2002, 96:242-249.

10. Epidemics of Meningococcal Disease, African Meningitis Belt, 2001. Wkly Epidemiol Rec 2001, 76:281-288.

11. Raghunathan PL, Jones JD, Tiendrebeogo SR, Sanou I, Sangare L, Kouanda S, Dabal M, Lingani C, Elie CM, Johnson S, et al.: Predictors of immunity after a major serogroup W-135 meningococcal disease epidemic, Burkina Faso, 2002. J Infect Dis 2006, 193:607-616.

12. WHO: Meningitis season 2007-2008: moderate levels of meningitis activity. In Global Alert and Response-Disease Outbreak News: Wold Health Organisation, Geneva; 2008.

13. 2001 - Meningococcal disease in the African Meningitis Belt - Update 3. In Global Alert and Response-Disease Outbreak News: World Health Organisation, Geneva; 2001.

14. Meningococcal disease in the African Meningitis Belt, epidemic season 2006. In Global Alert and Response-Disease Outbreak News: World Health Organisation; 2006

15. Expanded Program on Immunization (EPI) Wkly Epidemiol Rec 1997, 72:109-116.

16. Epidemic meningococcal disease--Kenya and Tanzania: recommendations for travelers, 1990. MMWR Morb Mortal Wkly Rep 1990 39:13-14.

17. Boisier P, Nicolas P, Djibo S, Taha MK, Jeanne I, Mainassara HB, Tenebray B, Kairo KK, Giorgini D, Chanteau S: Meningococcal meningitis: unprecedented incidence of serogroup X-related cases in 2006 in Niger. Clin Infect Dis 2007, 44:657-663.

18. WHO: Meningococcal disease in Saudi Arabia and the Netherlands Update. In Global Alert and Response-Disease Outbreak News: World Health Organisation; 2000
19. Safadi MA, Cintra OA: Epidemiology of meningococcal disease in Latin America: current situation and opportunities for prevention. Neurol Res 2010, 32:263-271.

20. Baker MG, Martin DR, Kieft CE, Lennon D: A 10-year serogroup B meningococcal disease epidemic in New Zealand: descriptive epidemiology, 1991-2000. J Paediatr Child Health 2001, 37:S13-19.

21. Mendsaikhan J, Watt JP, Mansoor O, Suvdmaa N, Edmond K, Litt DJ, Nymadawa P, Baoping Y, Altantsetseg D, Slack M: Childhood bacterial meningitis in Ulaanbaatar, Mongolia, 2002-2004. Clin Infect Dis 2009, 48 Suppl 2:S141-S146.

22. von Gottberg A, du Plessis M, Cohen C, Prentice E, Schrag S, de Gouveia L, Coulson $\mathrm{G}$, de Jong $\mathrm{G}$, Klugman $\mathrm{K}$ : Emergence of endemic serogroup W135 meningococcal disease associated with a high mortality rate in South Africa. Clin Infect Dis 2008, 46:377-386.

23. Annual Epidemiological Report 2012. Reporting on 2010 surveillance data and 2011 epidemic intelligence data. Stockholm: European Centre for Disease Prevention and Control.; 2013.

24. Trotter CL, Chandra M, Cano R, Larrauri A, Ramsay ME, Brehony C, Jolley KA, Maiden MC, Heuberger S, Frosch M: A surveillance network for meningococcal disease in Europe. FEMS Microbiol Rev 2007, 31:27-36

25. Kafetzis DA, Stamboulidis KN, Tzanakaki G, Kourea Kremastinou J, Skevaki CL, Konstantopoulos A, Tsolia M: Meningococcal group C disease in Greece during 1993-2006: the impact of an unofficial single-dose vaccination scheme adopted by most paediatricians. Clin Microbiol Infect 2007, 13:550-552.

26. Muscat M, Spiteri G, Calleja N, Haider J, Gray SJ, Melillo JM, Mamo J, Cuschieri P: Invasive meningococcal disease in Malta: an epidemiological overview, 1994-2007. J Med Microbiol 2009, 58:1492-1498.

27. Iversen BG, Aavitsland P: Meningococcal disease in Norway 1992-1995. Epidemiology and fatality. Scand J Infect Dis 1996, 28:253-259.

28. Meningococcal Disease [http://ec.europa.eu/health/ph_information/ dissemination/echi/docs/meningoccocal_en.pdf]

29. Dickinson FO, Perez AE: Bacterial meningitis in children and adolescents: an observational study based on the national surveillance system. BMC Infect Dis 2005, 5:103.

30. Guidelines for the early clinical and public health management of meningococcal disease in Australia. - Revised Edition 2007. Communicable Diseases Network Australia: Commonwealth Department of Health and Ageing; 2007.

31. Efron AM, Sorhouet C, Salcedo C, Abad R, Regueira M, Vazquez JA: W135 invasive meningococcal strains spreading in South America: significant increase in incidence rate in Argentina. J Clin Microbiol 2009, 47:1979-1980.

32. Whalen CM, Hockin JC, Ryan A, Ashton F: The changing epidemiology of invasive meningococcal disease in Canada, 1985 through 1992. Emergence of a virulent clone of Neisseria meningitidis. JAMA 1995, 273:390-394.

33. Bettinger JA, Scheifele DW, Le Saux N, Halperin SA, Vaudry W, Tsang R: The impact of childhood meningococcal serogroup $C$ conjugate vaccine programs in Canada. Pediatr Infect Dis J 2009, 28:220-224.

34. MacLennan J, Kafatos G, Neal K, Andrews N, Cameron JC, Roberts R, Evans MR, Cann K, Baxter DN, Maiden MC, Stuart JM: Social behavior and meningococcal carriage in British teenagers. Emerg Infect Dis 2006, 12:950-957.

35. Bae SM, Kang YH: Serological and genetic characterization of meningococcal isolates in Korea. Jpn J Infect Dis 2008, 61:434-437.

36. Vyse A, Wolter JM, Chen J, Ng T, Soriano-Gabarro M: Meningococcal disease in Asia: an under-recognized public health burden. Epidemiol Infect 2011:1-19.

37. Hu X: [Surveillance of epidemiological features for epidemic cerebrospinal meningitis in China during 1980s]. Zhonghua Liu Xing Bing Xue Za Zhi 1990, 11:321-324.

38. Shao Z, Li W, Ren J, Liang X, Xu L, Diao B, Li M, Lu M, Ren H, Cui Z, et al: Identification of a new Neisseria meningitidis serogroup $\mathrm{C}$ clone from Anhui province, China. Lancet 2006, 367:419-423.

39. Infectious Agents Surveillance Report. Meningococcal meningitis, 19992004, Japan. http://idsc.nih.go.jp/iasr/26/300/tpc300.html. (Report IAS ed., vol. 26. pp. 33-34; 2005:33-34.

40. Weekly Infectious Disease Bulletin-Ministry of Health, Singapore http://www.moh.gov.sg/content/dam/moh web/Statistics/ Infectious_Diseases_Bulletin/2011/December/2011_week_49.pdf. 2011.

41. Wilder-Smith A, Goh KT, Barkham T, Paton NI: Hajj-associated outbreak strain of Neisseria meningitidis serogroup W135: estimates of the attack rate in a defined population and the risk of invasive disease developing in carriers. Clin Infect Dis 2003, 36:679-683. 
42. Wang JL, Liu DP, Yen JJ, Yu CJ, Liu HC, Lin CY, Chang SC: Clinical features and outcome of sporadic serogroup W135 disease Taiwan. BMC Infect Dis 2006, 6:7.

43. Greenwood BM, Blakebrough IS, Bradley AK, Wali S, Whittle HC: Meningococcal disease and season in sub-Saharan Africa. Lancet 1984, 1:1339-1342.

44. Bishai DM, Champion C, Steele ME, Thompson L: Product development partnerships hit their stride: lessons from developing a meningitis vaccine for Africa. Health Aff (Millwood) 2011, 30:1058-1064.

45. Xie O, Pollard AJ, Mueller JE, Norheim G: Emergence of serogroup X meningococcal disease in Africa: need for a vaccine. Vaccine 2013, 31:2852-2861.

46. Sinclair D, Preziosi MP, Jacob John T, Greenwood B: The epidemiology of meningococcal disease in India. Trop Med Int Health 2010, 15:1421-1435.

47. Dell E, Bedford D, McMahon B, Nicholson A: Meningococcal disease-management of serogroup C clusters in a hyperendemic area. Ir Med J 2001, 94:166, 168-169.

48. Annual report of the Australian Meningococcal Surveillance Programme, 2009. Commun Dis Intell 2010, 34:291-302.

49. Prevention and control of meningococcal disease: recommendations for use of meningococcal vaccines in pediatric patients. Pediatrics 2005, 116:496-505.

50. Campagne G, Schuchat A, Djibo S, Ousseini A, Cisse L, Chippaux JP: Epidemiology of bacterial meningitis in Niamey, Niger, 1981-96. Bull World Health Organ 1999, 77:499-508.

51. Peltola H, Kataja JM, Makela PH: Shift in the age-distribution of meningococcal disease as predictor of an epidemic? Lancet 1982, 2:595-597.

52. Cartwright K, Noah N, Peltola H: Meningococcal disease in Europe: epidemiology, mortality, and prevention with conjugate vaccines. Report of a European advisory board meeting Vienna, Austria, 6-8 October, 2000. Vaccine 2001, 19:4347-4356.

doi:10.1186/1478-7954-11-17

Cite this article as: Jafri et al.: Global epidemiology of invasive meningococcal disease. Population Health Metrics 2013 11:17.

\section{Submit your next manuscript to BioMed Central and take full advantage of:}

- Convenient online submission

- Thorough peer review

- No space constraints or color figure charges

- Immediate publication on acceptance

- Inclusion in PubMed, CAS, Scopus and Google Scholar

- Research which is freely available for redistribution

Submit your manuscript at www.biomedcentral.com/submit
C Biomed Central 